\title{
The Importance of Anamnesis: A Case of Hypochlorite and Hydrochloric Acid Inhalation
}

\author{
Cihangir Doğu*, Nevzat Mehmet Mutlu, Ahmet Bindal, Tülay Tunçer Peker and Işıl Özkoçak Turan \\ Hittite University Corum Training and Research Hospital, Turkey
}

Submission: October 12, 2018; Published: October 24, 2018

*Corresponding author: Cihangir Doğu, T.C Sağlık Bakanlığı Hitit Üniversitesi Erol Olçok Reseach and Training Hospital, Tel: +903642193000; Email: cihangirdogu@gmail.com

\section{Summary}

We want to discuss a case of toxic substance inhalation which is one of the uncommon causes of severe respiratory failure in our article. The 42-year-old housewife was intubated in the emergency department with the complaint of dyspnea. The patient was transferred to intensive care unit. No pathology was found in cranial and thorax computerized tomography. Bronchoscopy revealed alveolar edema and bronchomalacia. Respiratory failure regressed, and the patient was extubated on the seventh day of hospitalization. It was learned from herself that the patient developed shortness of breath after the use of hypochlorite and hydrochloric acid for cleaning purposes. On the twelfth day of her admission, she was transferred to the infectious diseases ward. In this case, since the history of exposure was unknown, and no information learnt from the relatives of the patients, the differential diagnosis was difficult.

Keywords: Hypochlorite; Hydrochloric acid; Acute respiratory failure; History taking

Abbreviations: GCS: Glasgow Coma Scale; SIMV-V: Synchronized Intermittent Mandatory Ventilation-Volume control; PEEP: Positive End Expiratory Pressure; PCR: Polymerase Chain Reaction; ARDS: Acute Respiratory Distress Syndrome; ICU: Intensive Care Unit; CPAP: Continous Positive Airway Pressure

\section{Introduction}

With damage to the lung mucosa chlorine gas inhalation causes extensive pulmonary edema and acute respiratory distress syndrome. In this case report; We aimed to share the treatment process of a patient whose general condition worsened as a result of inhalation of the gas formed by the mixture of hypochlorite and hydrochloric acid.

\section{Case}

A 42-year-old woman without history of smoking was admitted to the emergency service with complaints of respiratory distress. In the emergency department, the patient was unconscious. Hypoxemia was detected in arterial blood gas analysis and endotracheal intubation was performed. Thoracic computed tomography revealed no pathological findings except atelectatic areas. Cranial computed tomography revealed no pathological findings to explain unconsciousness. She was referred to the emergency room of our hospital and she was admitted to our clinic at the 12th hour of intubation. APACHE II score was 14. It was learned that she had hypertension and Type-2 diabetes mellitus diseases. However, it was stated by the relatives that the patient did not use medication regularly. Physical examination at the admission to intensive care; The patient was agitated, GCS: 8, bilateral light reflexes were present, pupils were isochoric. Arterial blood pressure was $117 / 67 \mathrm{mmHg}$, heart rate was 123beats / min and rhythmic, and respiratory rate was 32 breaths / minute. The body temperature was $36.6{ }^{\circ} \mathrm{C}$, the breathing sounds were decreased on the left and no breathing sounds on the right. The expiration was long. Body mass index $(126 \mathrm{~kg} / 158 \mathrm{~cm})$ was 50.5 . She had abdominal distention.

C-reactive protein (41 mg / dL), white blood cell (21000 / dL) and lactate level $(5.1 \mathrm{mmol} / \mathrm{L})$ were observed in the laboratory.

On the anteroposterior chest X-ray (Figure-1), a decrease in ventilation was observed. Intubation tube was found to be in the right main bronchus. And drawn over the carina level. Mechanical ventilator mode was SIMV-V (tidal volume $450 \mathrm{ml}$, PEEP $6 \mathrm{~cm} \mathrm{H}_{2} \mathrm{O}$, respiratory rate 12 breaths / minute, PEEP above $8 \mathrm{~cm} \mathrm{H}_{2} \mathrm{O}$ ). Sedation (propofol $2 \mathrm{mg} / \mathrm{kg} / \mathrm{h}$, remifentanyl 0.1 microgram / kg / min) was applied for agitation. Bronchoscopy was performed to evaluate bronchial obstruction and there was no obstruction of the respiratory tract in both lungs but, alveolar edema and bronchomalacia were observed. Viral pneumonia and ARDS were considered. Thoracic tomography revealed no sign of ground glass opacities and the diagnosis of viral pneumonia was avoided. However, PCR was sent from bronchoalveolar lavage to confirm the diagnosis. Bacterial induced ARDS was suspected. With the recommendation of infectious diseases, intraveneous $3 \times 4.5$ grams of tazobactam-piperacillin were started. Right jugular internal cannulation was performed. On the second day 


\section{Juniper Online Journal of Case Studies}

of her hospitalization, sedation was terminated. Patient had spontaneous breathing and followed with CPAP mode. However, oxygen saturation drops to $85 \%$ and the mechanical ventilation switch to a controlled mode. (SIMV-V, tidal volume 450ml, PEEP $6 \mathrm{~cm} \mathrm{H}_{2} \mathrm{O}$, PEEP above $8 \mathrm{~cm} \mathrm{H}_{2} \mathrm{O}$, respiratory rate 12 breaths / $\min$ ). Figure 2 No pathology was recorded in the control chest x-ray. Sedation terminated on 3rd day of ICU. Hypoxia was observed after self-extubation and the patient was re-intubated. Bronchospasm episodes were observed, and viral PCR result was negative on the 3rd day of ICU stay. There was no positive growth in blood, urine, tracheal aspirate cultures after hospitalization.

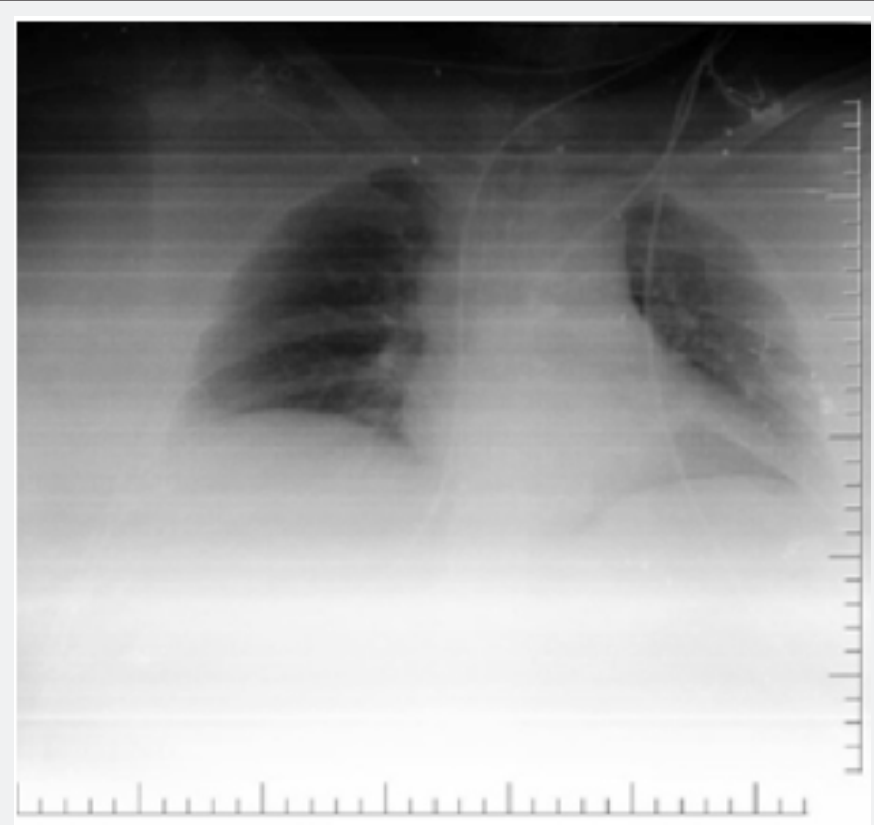

Figure 1: Posteroanterior chest radiography taken at admission to the service. Reduction in ventilation and endotracheal tube just above right main bronchus level.

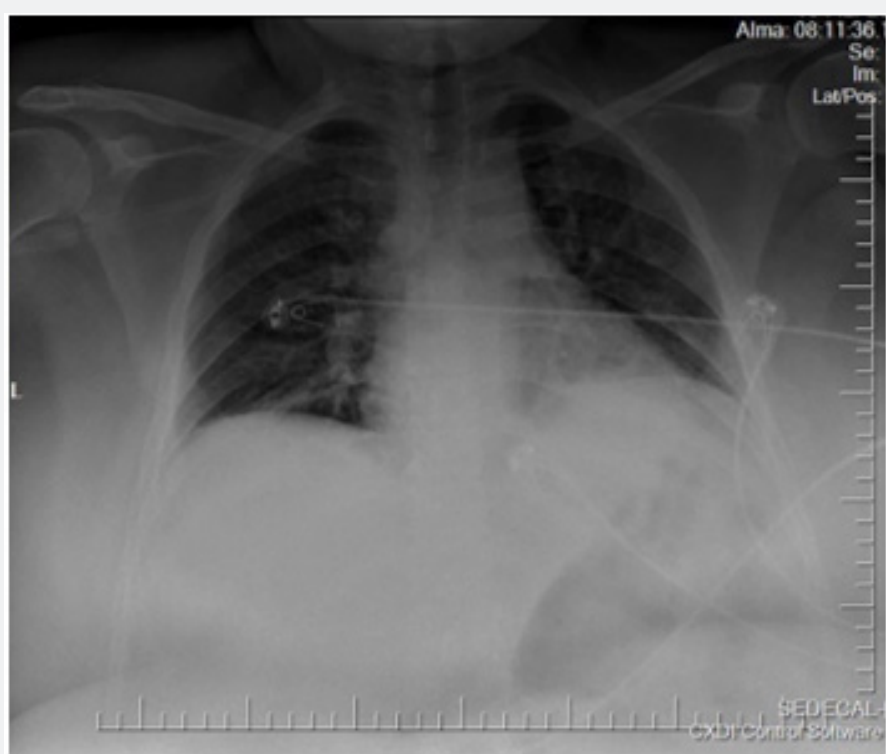

Figure 2: Posteroanterior chest radiography 11th day of ICU stay.

She was extubated on the 7th day of her hospitalization. The patient was followed for 4 days with non-invasive mechanical ventilation in CPAP mode after extubation.

In the anamnesis obtained from the patient after extubation, it was learned that the patient had exertional dyspnea before the event. It was learned that respiratory distress and loss of consciousness occurred approximately 30 minutes after cleaning with hypochlorite and hydrochloric acid mixture (salt spirit and bleach mixture). On the 10th day of her hospitalization, the patient had fever of $38,2{ }^{\circ} \mathrm{C}$ and purulent discharge was detected in the jugular central catheter entrance. Blood cultures were taken and central catheter was removed. The treatment of Tazobactam-piperacillin $3 \times 4,5$ grams were 


\section{Juniper Online Journal of Case Studies}

terminated and empirical meropenem $3 \times 1$ gram was started. Respiratory distress and bronchospasm attacks improved. There was no need for non-invasive respiratory support. On the 12th day of her admission to the intensive care unit, she was transferred to the infectious diseases department. Positive blood culture of Staphylococcus capitis reported on the 10th day of hospitalization. Staphylococcus capitis was produced on the 10th day of blood culture. Antibiotic regulation was not considered because it was sensitive to the current treatment.

\section{Discussion}

When sodium hypochlorite is dissolved in water, it turns into two reactive products as hypochloric acid $(\mathrm{HOCl})$ and hypochlorite $(\mathrm{OCl})$. These substances are antimicrobial without developing resistance at low concentration and are not threatening human life when used in accordance with warnings $[1,2]$.

Although toxic effects of chlorine on eyes, skin and heart are more common, lungs may also be affected when inhaled. As with the general pathological appearance of pulmonary poisonings, the first damage in lung after chlorine inhalation is seen in the respiratory epithelium. Chlorine is highly reactive and is extremely entrapped by the airway epithelium even at low concentrations. In case of low exposure, only airway damage is observed. At high dose exposure both airway and pulmonary edema could be observed and lead to alveolar damage [3].

Winder; showed that mild mucous membrane irritation occurred with 1-2 particles per million and pulmonary edema developed with 40-60 particles.1000 particles cause fatal damage within minutes [4].

Chlorine is released into the environment after the mixture of acid with hypochlorite [2]. Acute effects of high-level chlorine inhalation in humans are dyspnea, airway obstruction, cough, cyanosis, nausea, vomiting and loss of consciousness [5-7].

Güloğlu et al. [8] reported that five out of 106 people affected by the chlorine gas were treated in the intensive care unit. However, they reported that none of the patients needed mechanical ventilator support [8].

In June 2004, nine people died after a $54.422 \mathrm{~kg}$ chlorine gas spread to the environment in a train crash in the United States. This event; although it is in the open area, very high levels of chlorine gas can be fatal [9].

The reason why poisoning is more common in women all over the world is the frequent use of these substances in cleaning purposes [2]. In our patient's history which may be taken later, it was learned that respiratory distress and unconsciousness developed after cleaning. Although she was conscious in the emergency room she admitted first, no history could be received from the patient herself. Because the patient's relatives did not have enough information, she intubated and sedated due to hypoxia and delayed the diagnosis of chlorine exposure and led to other diagnoses. Bronchoscopic evaluation of the lungs due to lack of ventilation revealed tracheobronchitis, negative pressure pulmonary edema and bronchomalacia.

One of the reasons for the clinical picture of our case is serious and the need for mechanical ventilator development is a high concentration exposure in a narrow and closed environment during toilet cleaning. In addition, the patient's morbid obesity and the presence of exertion dyspnea may have aggravated the clinical picture. The fact that the relatives of the patients did not know the history of exposure caused a delay in the diagnosis of hypochlorite inhalation. The cause of pulmonary edema was thought to be the result of viral and bacterial pneumonia and the research was deepened on this aspect. The main cause of respiratory distress was learned from the patient herself after extubation.

We had to perform sedation intermittently because of agitation, which may be among the reasons that make it difficult to wean from the ventilator. The patient's self-extubations also increased the risk of aspiration.

\section{Conclusion}

In case of hypochlorite intoxication, eyes, skin and heart may be affected. The highest effects are seen on the lungs and may cause severe respiratory failure. General support and respiratory close monitoring are recommended. If necessary, treatment should be performed with invasive respiratory support. We think that it would be useful to evaluate the irritant gas exposure in the differential diagnosis in acute respiratory failure without any history.

\section{References}

1. Carpenter A, Cox AT, Marion D, Phillips A, Ewington I (2016) A case of chlorine inhalation injury in an Ebola treatment unit. J R Army Med Corps 162(3): 229-231.

2. Racioppi F, Daskaleros PA, Besbelli N, Borges A, Deraemaeker C, et al. (1994) Household bleaches based on sodium hypochlorite: review of acute toxicology and poison control center experience. Food Chem Toxicol 32(9): 845-861.

3. Nodelman V, Ultman JS (1999) Longitudinal distribution of chlorine absorption in human airways: comparison of nasal and oral quiet breathing. J Appl Physiol (1985) 86(6): 1984-1993.

4. Winder C (2001) The toxicology of chlorine. Environ Res 85(2): 105114.

5. Becking AG (1991) Complications in the use of sodium hypochlorite during endodontic treatment. Oral Surg Oral Med Oral Path 71(3): 346-348.

6. Ziegler DS (2001)Upper airway obstruction induced by a caustic substance found responsive to nebulised adrenalin. J Paed Child Health 37(5): 524-525.

7. Adelson L, Kaufman J (1971) Fatal chlorine poisoning: report of two cases with clinicopathologic correlation. Am J Clin Pathol 56(4): 430442.

8. Cahfer Güloğlu, İsmail Hamdi Kara, Pakize Gamze Erten (2002) Acute Accidental Exposure to Chlorine Gas in the Southeast of Turkey: A Study of 106 Cases Environmental Research Section A 88,89: 93.

9. Joyner RE, Durel EG (1962) Accidental liquid chlorine spill in a rural community. J Occup Med 4(3): 152-154. 
Your next submission with Juniper Publishers will reach you the below assets

- Quality Editorial service

- Swift Peer Review

- Reprints availability

- E-prints Service

- Manuscript Podcast for convenient understanding

- Global attainment for your research

- Manuscript accessibility in different formats

( Pdf, E-pub, Full Text, Audio)

- Unceasing customer service

Track the below URL for one-step submission https://juniperpublishers.com/online-submission.php 